\title{
Prostate field cancerization and exosomes: Association between CD9, early growth response 1 and fatty acid synthase
}

\author{
FARIDEH AMIRRAD ${ }^{1}$, PHILIP A. PYTAK ${ }^{2}$, NEDA SADEGHIANI-PELAR ${ }^{1}$, \\ JULIE P.T. NGUYEN ${ }^{2}$, EMILY L. CAUBLE ${ }^{3}$, ANNA C. JONES ${ }^{4}$ and MARCO BISOFFI ${ }^{1-3}$ \\ ${ }^{1}$ Department of Biomedical and Pharmaceutical Sciences, Chapman University School of Pharmacy, \\ Harry and Diane Rinker Health Science Campus, Irvine, CA 92618; ${ }^{2}$ Division of Chemistry and Biochemistry, and ${ }^{3}$ Division \\ of Biological Sciences, Chapman University Schmid College of Science and Technology, Keck Center for Science and \\ Engineering, Orange, CA 92866; ${ }^{4}$ University of New Mexico Comprehensive Cancer Center, Albuquerque, NM 87102, USA
}

Received August 8, 2019; Accepted January 23, 2020

DOI: $10.3892 /$ ijo.2020.4980

\begin{abstract}
Intracapsular and well-defined adenocarcinomas of the prostate are often surrounded by tissue areas that harbor molecular aberrations, including those of genetic, epigenetic and biochemical nature. This is known as field cancerization, or a field effect and denotes a state of pre-malignancy. Such alterations in histologically normal tumor-adjacent prostatic tissues have been recognized as clinically important and are potentially exploitable as biomarkers of disease and/or targets for preventative/therapeutic intervention. The authors have previously identified and validated two protein markers of field cancerization: The expressional upregulation of the transcription factor early growth response 1 (EGR-1) and the lipogenic enzyme fatty acid synthase (FASN). However, the molecular etiology of prostate field cancerization, including EGR-1 and FASN upregulation, remains largely unknown. It was thus hypothesized that extracellular vesicles, notably exosomes, released by tumor lesions may induce molecular alterations in the surrounding tissues, resulting in field cancerization, priming the tissue, and ultimately promoting multifocal tumorigenesis, which is often observed in prostate cancer. Towards testing this hypothesis, the current study, to the best of our knowledge, for the first time, presents correlative protein expression data, generated in disease-free, tumor-adjacent and cancerous human prostate tissues by quantitative immunofluorescence, between the exosomal marker CD9, and EGR-1 and FASN. Despite the pilot character of the present study, and the static nature and heterogeneity of human tissues, the data suggest that CD9 expression itself is
\end{abstract}

Correspondence to: Dr Marco Bisoffi, Division of Chemistry and Biochemistry, Chapman University Schmid College of Science and Technology, Keck Center for Science and Engineering, 1 University Drive, Orange, CA 92866, USA

E-mail: bisoffi@chapman.edu

Key words: prostate cancer, field cancerization, exosomes, CD9, early growth response 1 , fatty acid synthase part of a field effect. In support of this hypothesis, the results suggest a possible contribution of exosomes to the induction of field cancerization in the prostate, particularly for EGR-1. These findings were corroborated in established cell models of cancerous (LNCaP) and non-cancerous (RWPE-1) human prostate epithelial cells. The findings of this study warrant further investigation into the functional interface between exosomes and field cancerization, as a detailed understanding of this characterization may lead to the development of clinical applications related to diagnosis and/or prognosis and targeted intervention to prevent progression from pre-malignancy to cancer.

\section{Introduction}

Since the otolaryngologist Danely Slaughter introduced the concept of field cancerization in 1953 in stratified squamous epithelia of the oral mucosa of patients suffering from oral diseases (1), the definition of this term, also known as the field effect, field defect, or field carcinogenesis, has changed mainly due to the rapid development of analytical techniques in molecular biology and genetics developed over the past decades. First, the original intent was to describe the occurrence of cancerous cells in histologically normal tissues at some distances from the primary lesions, and to explain the multifocality of solid tumors, particularly in the case of oral cancers, including squamous cell carcinomas $(1,2)$. These cells are by definition clinically detectable. By contrast, the current definition of field cancerization applies to structurally and phenotypically intact cells residing in histologically normal tissues outside the confinement of the primary tumor. These cells do not typically distinguish themselves from their surrounding and thus remain clinically hidden. The latter points to the second major change of the term 'field cancerization', i.e., the shift in focus on the molecular characterization of affected cells and tissues, as opposed to their phenotypical appearance (3). Consequently, cells that are part of 'field cancerized' tissues are considered to be molecularly altered in the absence of other visually obvious changes. Furthermore, the nature of these molecular alterations is typically indicative of a positively 'primed' or 'committed' status with respect to 
cell proliferation, growth, migration and/or survival, essentially delineating the affected cells as pre-malignant (4-6). The authors have continuously contributed to the molecular characterization of field cancerization in prostate tissues by describing both genetic and biochemical deviations from normalcy (7-13). This has included the observation of telomere attrition (9), as well as the upregulation of protein expression, including the key transcription factor early growth response 1 (EGR-1) and the anabolic enzyme fatty acid synthase (FASN) $(7,11)$.

Although the importance of field cancerization in representing a type of pre-malignancy in tissues that are prone to tumorigenesis has been recognized and acknowledged, the molecular and cellular mechanisms underpinning its etiology, while often discussed, remain largely unknown (4-6). This is also true for field cancerization in prostatic tissues and stands in contrast to the growing list of molecular and cellular markers describing it $(13,14)$. A recent focus in urological research has been the functional role of extracellular vesicles released by virtually all types of cells in the prostate as part of inter-cell and inter-organ compartment communication $(15,16)$. These extracellular vesicles include exosomes that have been characterized to be in the range of 30-150 nanometers in diameter. The importance of exosomal function in normal prostate physiology has been well recognized and is primarily due to their biologically active 'cargo' that includes multiple types of RNAs, lipids and proteins (17-20). Conceptually, the biochemical composition of exosomes reflects the current physiology of the cell of origin. It is thus not inconceivable to assume that a specific physiological signature can be conveyed or transferred to recipient cells. This line of thought has led to the hypothesis of a potential role of exosome release and action in the etiology of field cancerization. The authors have thus begun to test this hypothesis by assessing a potential correlation in protein expression between the exosomal marker and tetraspanin, CD9, and the afore-mentioned field cancerization markers, EGR-1 and FASN, in human prostate tissues. Cultured cell models of prostate cancer were also used to corroborate these findings. The results indicate a possible association between exosomes and the expression of EGR-1 and potentially, that of FASN in prostate tissues affected by field cancerization. This novel insight into pathways underlying prostate field effect may lead to the development of targeted intervention strategies preventing progression from pre-malignancy to cancer.

\section{Materials and methods}

Tissues and cells. Tissue microarrays (TMAs) were purchased from US Biomax, Inc. (https://www.biomax.us/). No human tissues from other sources, other than commercially available TMAs, were used in the present study. The use of any human tissues, including commercially available TMAs, is covered by the Chapman University Institutional Review Board (IRB) study \#1415H024. For the present study, the formalin-fixed and paraffin-embedded (FFPE) TMA BC 19021a was used, featuring 5- $\mu \mathrm{m}$-thick cancerous, tumor-adjacent and disease-free (normal) human prostate tissue cores of $1.5 \mathrm{~mm}$ in diameter. Experiments with human tissues was approved by the Institutional Review Board of Chapman University. The tissue cohort analyzed in this study consisted of 8 adenocarcinomas,
8 tumor-adjacent tissues, and 6 disease-free tissues. These were selected for inclusion to represent variation in age and tumor stage and based on immunofluorescence quality. The matching status of the tumor-adjacent tissues with the featured tumors is unknown. Also unknown was the distance from the tumor margin at which adjacent tissues were resected. However, a common practice in our own research is resection at a distance of approximately $1 \mathrm{~cm}$ from the visible tumor margin $(7-11,21)$. The definition of the term 'disease-free' refers to prostate specimens from autopsy cases from individuals who died due to conditions unrelated to cancer. The mean age of all cases utilized was 54.7 years with a range of 21-80 years. The cancer specimens featured Gleason scores from 4 to 10 and pathological tumor node metastasis (TNM) stages (according to the American Joint Committee on Cancer; https://cancerstaging.org/Pages/default.aspx) from T2aN0M0 to T2N1M1b (Table I).

Non-cancerous RWPE-1 and cancerous LNCaP human prostate epithelial cells were purchased from the American Type Culture Collection (ATCC) and cultured in serum-free keratinocyte basal medium containing 4,500 mg/l glucose, $0.05 \mathrm{mg} / \mathrm{ml}$ bovine pituitary extract and $5 \mathrm{ng} / \mathrm{ml}$ recombinant epidermal growth factor (EGF) (for RWPE-1), or in RPMI-1640 medium supplemented with $10 \%$ heat-inactivated $\left(56^{\circ} \mathrm{C}, 1 \mathrm{~h}\right)$ fetal bovine serum (FBS) and $100 \mathrm{U} / \mathrm{ml}$ penicillin/streptomycin (for LNCaP). Cells were maintained at $37^{\circ} \mathrm{C}$ in a humidified $5 \% \mathrm{CO}_{2}$ atmosphere. Trypsin-EDTA at $0.25 \%$ was used to detach the cells for splitting and re-culturing.

Immunofluorescence. Immunofluorescence was performed as described in previous studies by the authors on prostate field cancerization $(7,10,11)$. In order to query the same tissue areas for the three protein markers under investigation (CD9, EGR-1 and FASN), consecutive sections, each $5 \mu \mathrm{m}$ apart from each other were used (Fig. 1). TMAs were subjected to deparaffinization with xylene and rehydrated with decreasing concentrations of ethanol. Antigen retrieval was performed in boiling $10 \mathrm{mM}$ Tris, $1 \mathrm{mM}$ EDTA, 0.05\% Tween-20, pH 9.0 (by $\mathrm{HCl}$ ) for $10 \mathrm{~min}$, washed briefly in tap water, followed by gentle agitation in Tris buffered saline (TBS; $50 \mathrm{mM}$ Tris, $150 \mathrm{mM} \mathrm{NaCl}, \mathrm{pH} 7.6$ by $\mathrm{HCl}$ ) containing $0.025 \%$ Triton $\mathrm{X}-100$ (TBST). Tissues were blocked in 10\% normal goat serum (sc-2040, Santa Cruz Biotechnology) in TBS containing $1 \%$ bovine serum antigen (BSA) for $2 \mathrm{~h}$ at room temperature, then incubated with primary antibodies in TBS containing $1 \% \mathrm{BSA}$ at $4^{\circ} \mathrm{C}$ overnight. These were all mouse monoclonal antibodies from Abcam used at $3 \mu \mathrm{g} / \mathrm{ml}$ : Anti-CD9 (ab2215), anti-EGR-1 (ab55160) and anti-FASN (ab218306). The control antibody to ensure target specificity at the same concentration was normal mouse IgG (GC270, Millipore). The corresponding secondary antibody, used at a dilution of 1:750, was Alexa Fluor 594-conjugated goat anti-mouse IgG (A11005, Life Technologies; Thermo Fisher Scientific; excitation at $590 \mathrm{~nm}$, emission at $618 \mathrm{~nm}$ ). Nuclear counterstaining was performed with diamidino-2-phenylindole (DAPI) in TBS for $2 \mathrm{~min}$. Fluorescence was preserved using Fluoroshield solution (Sigma) under coverslips sealed with nail polish. Cells were cultured and prepared for qualitative immunofluorescence concomitantly (on the same slide) on Millicell EZ slides (Millipore) to ensure equal experimental and thus comparative 
Table I. Demographics and clinical parameters of prostate tissues, and the no. of images analyzed.

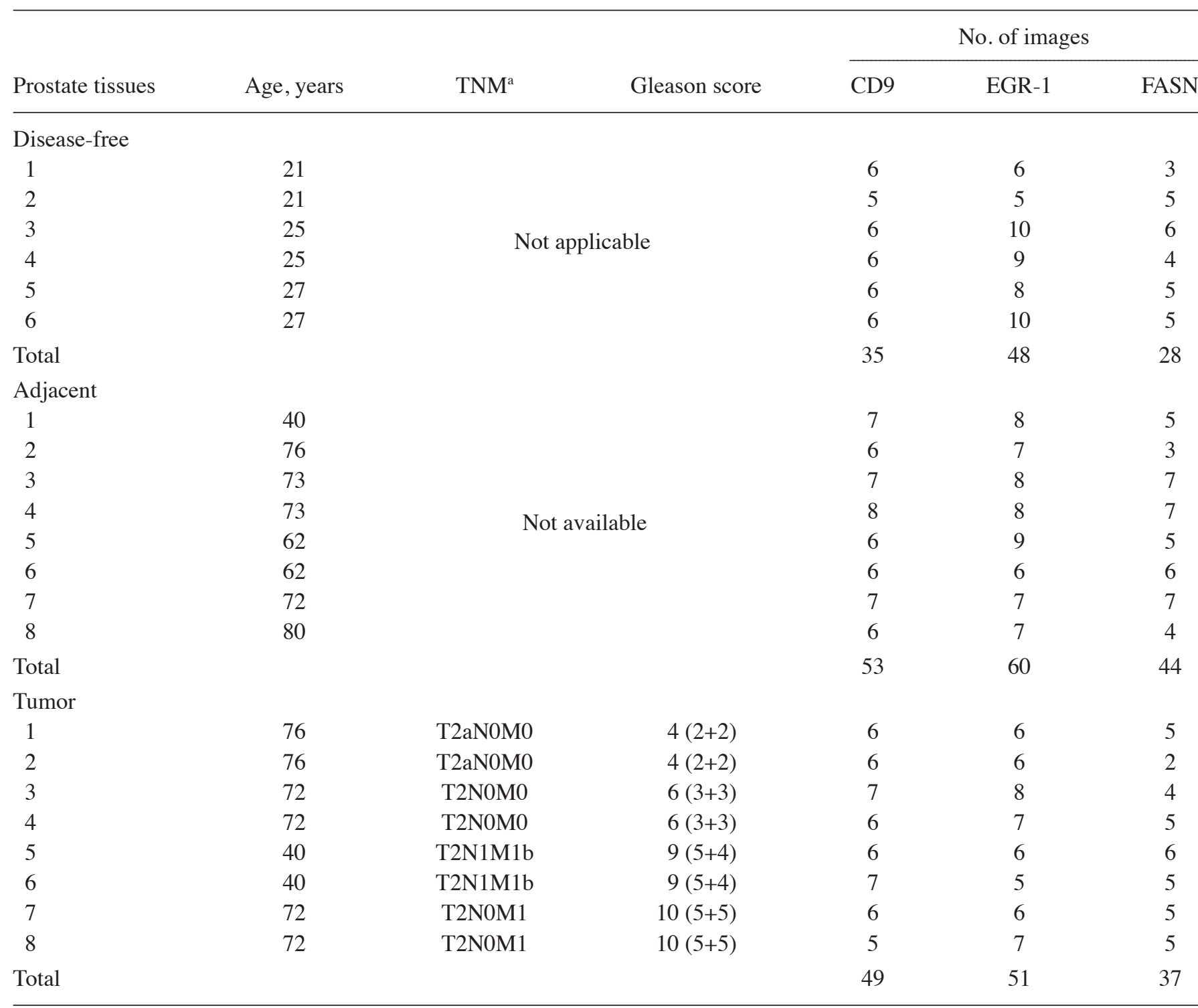

A total of 8 adenocarcinomas (tumor), 8 tumor adjacent tissues (adjacent), and 6 disease-free tissues were analyzed. In total, 336 images were queried (numbers for each case and marker are indicated). ${ }^{\text {a }}$ Tumor nodes netastasis (TNM) pathological stage was assigned using criteria published by the American Joint Committee on Cancer (https://cancerstaging.org/Pages/default.aspx). EGR-1, early growth response 1; FASN, fatty acid synthase.

treatment. The cells were fixed in $4 \%$ formaldehyde followed by 3 washes in TBS and stained as for the tissues above.

Fluorescence for both cells and tissues was detected using an A1R Nikon confocal microscope available at the Chapman University School of Pharmacy Microscopy Core Facility. For the tissues, fluorescence was quantified using the NIS-Elements AR 4.30.02/64bit software to analyze acquired digital images. Consistent with previous studies by the authors $(7,10,11)$, the fluorescence signal acquisition mode was applied to 2-10 images per tissue sample. Great care was taken in choosing tissue areas with as equal as possible numbers of DAPI-stained nuclei from epithelial compartments to account for equal number of cells analyzed. In addition, identical areas on the consecutive sections were imaged for the three specific protein markers (CD9, EGR-1 and FASN) to allow the reported correlation analyses. For all specific markers, the acquisition setting was kept identical for all images taken to ensure the validity of intra- and inter-tissue comparisons. The number of images amenable to quantitative fluorescence analysis per individual tissue and protein marker under investigation is indicated in Table I. In total, 336 images with associated quantitative immunofluorescence data were available for the present analysis.

Isolation of exosomes. Exosomes were isolated from cancerous LNCaP and from non-cancerous RWPE-1 cells according to the Current Protocols in Cell Biology (John Wiley \& Sons, Inc.) using ultracentrifugation in an Optima XE-90 ultracentrifuge (Beckman Coulter). Cells grown to $80 \%$ confluency in complete growth medium were washed twice in medium 

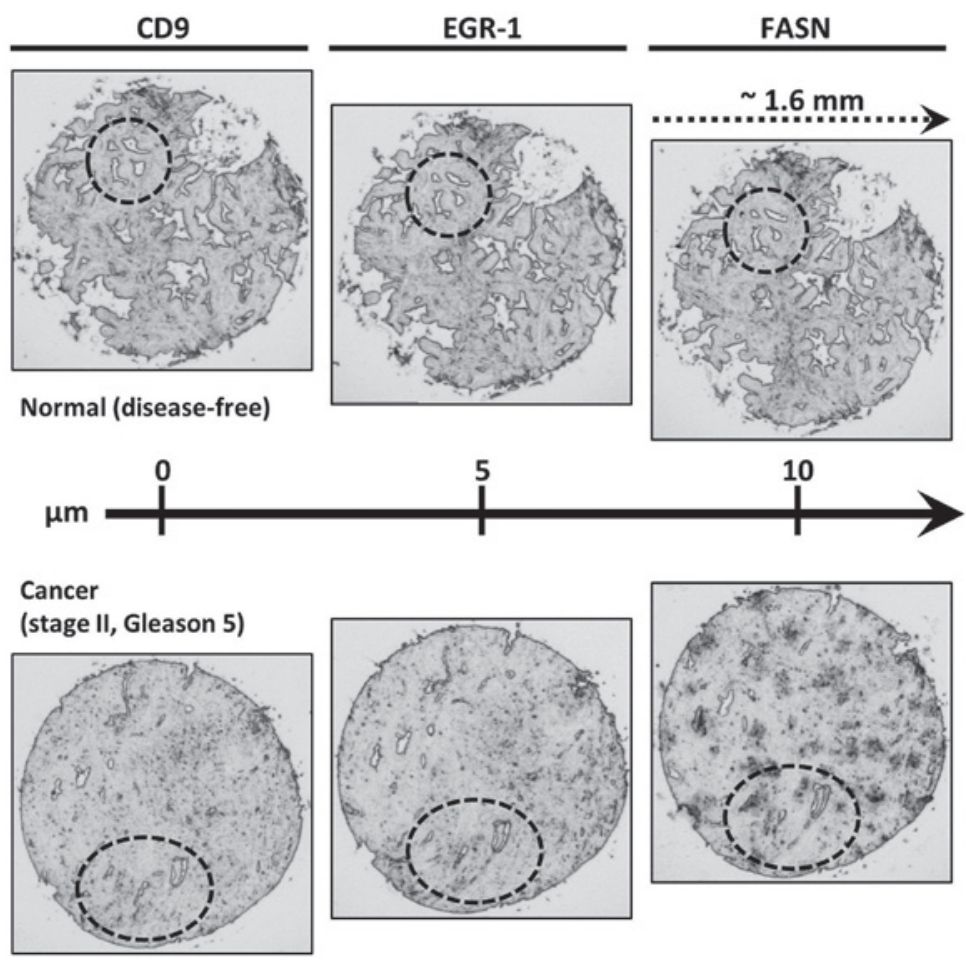

Figure 1. Representative consecutive sections of normal (disease-free) and cancerous (stage II, Gleason score of 5) human prostate tissues from a human tissue microarray utilized in quantitative immunofluorescence. The sections are approximately $5 \mu \mathrm{m}$ apart from each other, which allows to analyze near-identical areas for the expression of different markers (CD9, EGR-1 and FASN), indicated by the dashed circles. Images were acquired by phase contrast light microscopy. EGR-1, early growth response 1; FASN, fatty acid synthase.

without serum, then incubated at $37^{\circ} \mathrm{C}$ for $48 \mathrm{~h}$ in medium containing $10 \%$ exosome-free FBS. Exosome-free FBS was prepared by a 2 -h long ultracentrifugation of medium/20\% FBS at $100,000 \mathrm{x} \mathrm{g}$ at $4^{\circ} \mathrm{C}$ to pellet exosomes stemming from the FBS. Upon collection of the medium from the cells, it was subjected to the following sequential centrifugation procedure (all steps at $4^{\circ} \mathrm{C}$ ): i) $300 \mathrm{xg}$ for $10 \mathrm{~min}$ to remove live cells; ii) $2,000 \mathrm{x}$ g for $10 \mathrm{~min}$ to remove dead cells; iii) $10,000 \mathrm{x} \mathrm{g}$ for $30 \mathrm{~min}$ to remove cell debris; iv) $100,000 \mathrm{x}$ g for $2 \mathrm{~h}$ to pellet the exosomes; v) the resulting pellet was washed in phosphate buffered saline (PBS) to remove contaminating proteins and recentrifuged at $100,000 \mathrm{x} g$ for $2 \mathrm{~h}$ to obtain exosomes of high purity; vi) the final pellet was resuspended in a small volume of PBS, typically $150 \mu \mathrm{l}$ for an original of $40 \mathrm{ml}$ culture supernatant. Exosomes were aliquoted and stored short-term at $-80^{\circ} \mathrm{C}$ with avoidance of multiple freeze-thaw cycles. The amount and viability of cells giving rise to the exosomes was determined by trypan blue exclusion assay and the cells were frozen at $-80^{\circ} \mathrm{C}$ for western blot analysis (please see below).

The morphology of the isolated exosomes was further characterized by atomic force microscopy using an MFP-3D origin atomic force microscope (AFM; Asylum Research). A $25 \mu 1$ aliquot was dropped on amine-functionalized (3-aminopropyl) trimethoxysilane (APTMS) glass cover slips and dried in air. The cover slips were washed by sonication with water, acetone, ethanol and isopropyl alcohol before re-soaked in an ethanol solution of APTMS for $2 \mathrm{~h}$. Conical-shaped silicon AFM probes with $\mathrm{Al}$ reflex coating $(\mathrm{k}=42 \mathrm{~N} / \mathrm{m})$ were mounted on the cantilever holder and operated in AC mode. AFM data were processed using MFP3D software written in an IgorPro environment (Wavemetrics). Exosome dimensions on the digitized images were quantified using ImageJ software (https://imagej.nih.gov/ij/).

Treatment of cells with exosomes. RWPE-1 cells were seeded in 6-well plates at a density of $0.5 \times 10^{6}$ cells per well and incubated at $37^{\circ} \mathrm{C}$ for settlement and growth for $24 \mathrm{~h}$. Either 5 or $50 \mu \mathrm{g}$ of LNCaP or $50 \mu \mathrm{g}$ RWPE-1 exosomes (as a negative control), corresponded to $1.5 \times 10^{6}$ and $15.0 \times 10^{6}$ exosome-producing cells, respectively. The cells were incubated at $37^{\circ} \mathrm{C}$ for $24 \mathrm{~h}$, washed twice in PBS following the removal of the supernatant, and collected by either scraping or trypsinization followed by mild centrifugation at $2,600 \mathrm{x}$ g for $10 \mathrm{~min}$ at $4^{\circ} \mathrm{C}$. Cell pellets were snap-frozen in liquid nitrogen to preserve RNA and protein integrity and were stored short term at $-80^{\circ} \mathrm{C}$. Scraped and trypsinized cells were used for analysis by western blot analysis and reverse transcription-quantitative polymerase chain reaction (RT-qPCR), respectively (please see below).

Western blot analysis. Western blot analysis was performed on both the cultured cells and the exosomes derived therefrom. Protein lysates were generated on ice in lysis buffer: $25 \mathrm{mM}$ Tris, $8 \mathrm{mM} \mathrm{MgCl}_{2}, 1 \mathrm{mM}$ DTT, $15 \%$ glycerol, $1 \%$ Triton X-100 and protease inhibitor cocktail (Sigma). Insoluble material was removed by centrifugation of the lysates at $20,000 \mathrm{x} \mathrm{g}$ for $10 \mathrm{~min}$ at $4^{\circ} \mathrm{C}$. The protein concentration was determined by Bradford assay (Sigma) against a bovine serum albumin (BSA) standard. In total, $80 \mu \mathrm{g}$ (for cell lysates) or $20 \mu \mathrm{g}$ (for exosomal lysates) total protein were size-separated by sodium dodecyl sulfate polyacrylamide gel electrophoresis (SDS-PAGE) and electro-transferred onto polyvinylidene (PVDF) membranes. The membranes were stained with 


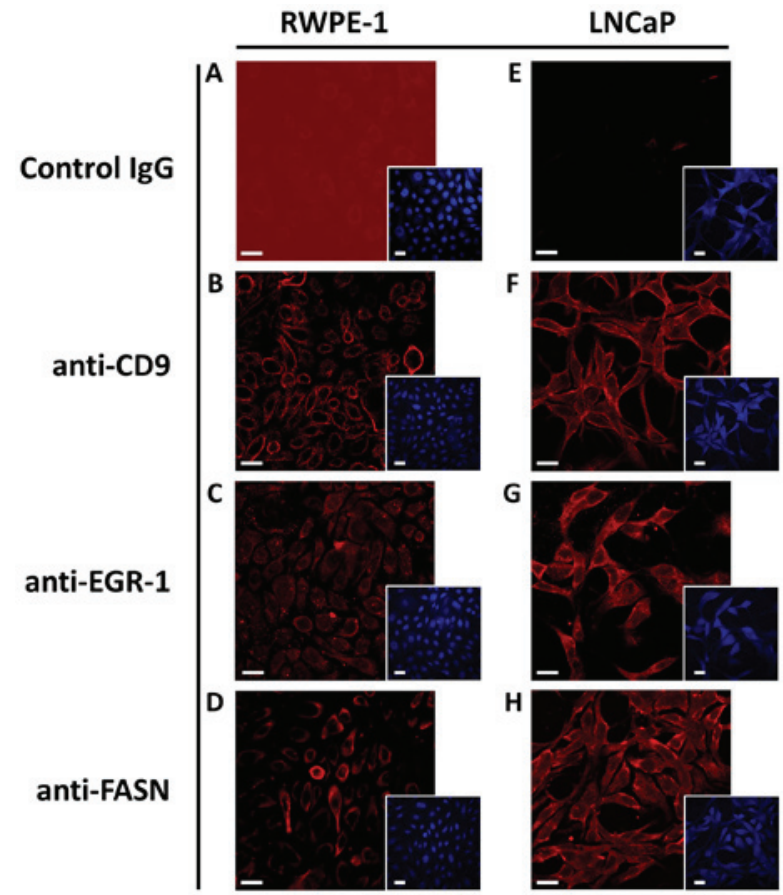

Figure 2. Immunostaining with control IgG (for background/absent staining) anti-CD9, anti-EGR-1 and anti-FASN antibodies in human non-cancerous RWPE-1 (A-D) and cancerous LNCaP (E-H) prostate cells. Images illustrate fluorescence detected with Alexa Fluor 594 (red; excitation at 590 nm, emission at $618 \mathrm{~nm}$ ). The smaller insets illustrate the same image (size reduced) and stained with nuclear DAPI (blue) for single cell identification. Scale bars (white bars) in all images represent $10 \mu \mathrm{m}$. EGR-1, early growth response 1; FASN, fatty acid synthase.

0.1\% Ponceau S [3-hydroxy-4-(2-sulfo-4-[4-sulfophenylazo] phenylazo)-2,7-naphthalenedisulfonic acid; Sigma] in $5 \%$ acetic acid for $5 \mathrm{~min}$ at room temperature to visualize the blotted proteins. Following 2 brief washes in TBS, the membranes were blocked with $5 \%$ milk powder in TBS containing $0.05 \%$ Tween-20 (TBST) and probed overnight at $4^{\circ} \mathrm{C}$ with the anti-CD9, anti-EGR-1 and anti-FASN antibodies listed above in the 'Immunofluorescence' paragraph, and with anti-androgen receptor (AR) antibody (sc-816; AR (N-20), Santa Cruz Biotechnology), and with anti- $\beta$-actin antibody (A1978, Sigma) (for cell extracts) and anti-actin antibody (A3853, Sigma) (for exosomes extracts) at typical concentrations of $0.2 \mu \mathrm{g} / \mathrm{ml}$ in TBST. The detection and chemiluminescent visualization (Clarity ECL Substrate, Bio-Rad) of target proteins was performed using secondary horseradish peroxidase-conjugated goat anti-mouse (A0168; Sigma) and goat anti-rabbit (A0546; Sigma) antibodies used at 1:15,000 dilutions for $1 \mathrm{~h}$ at room temperature. Band intensity (expression level) was quantified by densitometry using ImageJ software (https://imagej.nih.gov/ij/).

$R T-q P C R$. RNA was isolated using spin column chromatography (Qiagen). In total, 1-3 $\mu \mathrm{g}$ of RNA was transcribed into cDNA using random decamers of the Retroscript RT kit (Life Technologies; Thermo Fisher Scientific). mRNA expression was quantitated in a CFX Connect Real Time PCR Detection System from Bio-Rad using the SYBR-Green PCR Master Mix and SYBR-Green RT-PCR Reagents kit (Life Technologies; Thermo Fisher Scientific) in $25 \mu 1$ reactions,

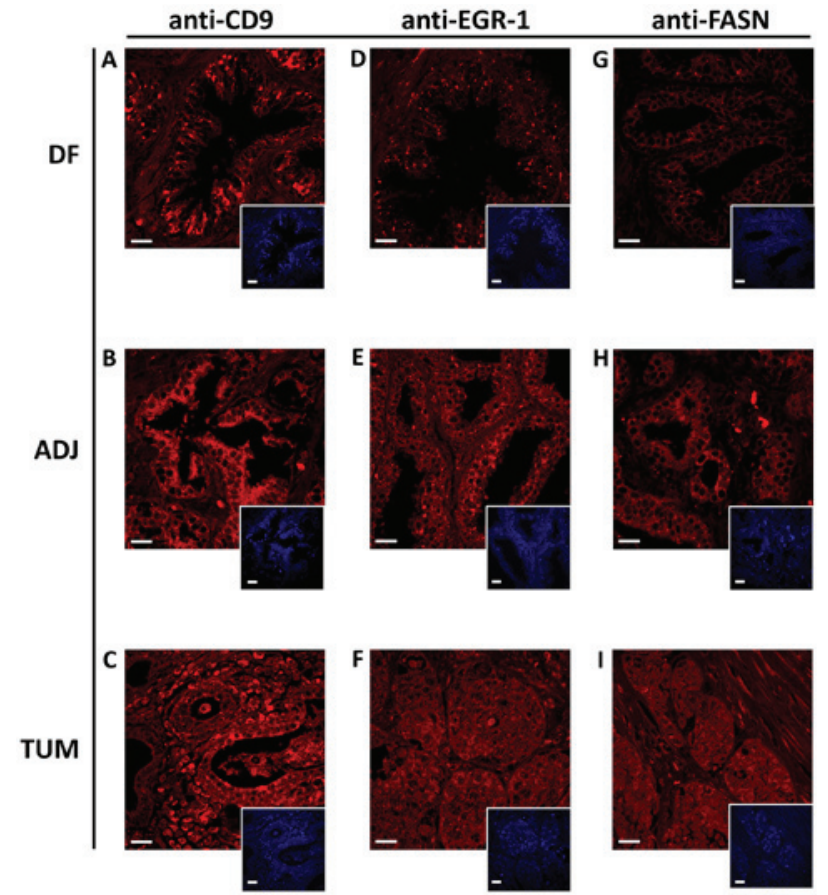

Figure 3. Representative detection of CD9, EGR-1 and FASN by immunofluorescence in disease-free (DF; A, D and G), tumor-adjacent (ADJ; $\mathrm{B}, \mathrm{E}$ and $\mathrm{H}$ ), and tumor (TUM; C, F and I) human prostate tissues. Images illustrate fluorescence detected with Alexa Fluor 594 (red; excitation at $590 \mathrm{~nm}$, emission at $618 \mathrm{~nm}$ ). The smaller insets illustrate the same image (size reduced) and stained with nuclear DAPI (blue) for single cell identification. Scale bars (white bars) in all images represent $10 \mu \mathrm{m}$. EGR-1, early growth response 1; FASN, fatty acid synthase.

using $100 \mathrm{ng}$ of template cDNA and a final primer concentration of $900 \mathrm{nM}$. The cycling parameters were $95^{\circ} \mathrm{C}$ for $5 \mathrm{~min}$ followed by 45 cycles of $94^{\circ} \mathrm{C}$ for $15 \mathrm{sec}$ and $60^{\circ} \mathrm{C}$ for $1 \mathrm{~min}$. Primers were designed using Primer Express software (Invitrogen; Thermo Fisher Scientific) and synthesized by Integrated DNA Technologies. The following primer sequences (5' to 3') were used: EGR-1 forward, GAGCAGCCCTAC GAGCAC and reverse, AGCGGCCAGTATAGGTGATG; FASN forward, AGAACTTGCAGGAGTTCTGGGACA and reverse, TCCGAAGAAGGAGGCATCAAACCT; TATA binding protein (TBP) forward, CACGAACCACGGCAC TGATT and TBPreverse, TTTTCTTGCTGCCAGTCTGGAC. RT-qPCR reactions were performed in triplicate. Relative expression levels were determined by the $\Delta \Delta \mathrm{Cq}$ method (22) using TBP as the normalization control after determining that amplification efficiencies were similar to the ones of the control transcripts.

Statistical analysis. CD9, EGR-1 and FASN expression levels are represented by signal intensities (sum pixel count per area) generated by quantitative immunofluorescence analysis (as described above). Simple, yet straightforward statistical methods were applied to the datasets using the Microsoft Office Excel software package. Due to our previously observed and well-known intra- and inter-specimen heterogeneity in tissue expression studies $(7,10,11)$, the datasets were inclusive, i.e., all available informative images were utilized, and no computational calculation was used to identify potential outliers. The infinite variance due to tissue heterogeneity is 
expressed as the coefficient of variation in \% in the text of the 'Results' section. Single factor analysis of variance (ANOVA) was used to compare multiple datasets with unequal variances. The post hoc Fishers' least significant difference (LSD) test was used to determine the significance of the difference between the means of the datasets. ANOVA followed by LSD was also used to analyze the results of western blot analysis and RT-qPCR. Statistical significance in these comparisons of the means was defined as $\mathrm{P} \leq 0.05$. The datasets were mined for potential associations between CD9 and EGR-1 and between CD9 and FASN by determining the Pearson's correlation coefficient $r$. The significance for these observations was determined by first calculating the $t$-value of the correlation using the equation $t=r / \operatorname{SQRT}\left(1-r^{2} / n-2\right)$, where ' $r$ ' is the correlation coefficient, ' $\mathrm{n}$ ' is the number of samples, and ' 2 ' is the degree of freedom. The t-value was then used to determine the significance of ' $r$ ' by the two-tailed Student t-distribution (TDIST; statistical significance defined as $\mathrm{P} \leq 0.05$ ).

\section{Results}

Detection of CD9, EGR-1 and FASN expression in human prostate cells and tissues. The antibodies used to detect CD9, EGR-1 and FASN by immunofluorescence in human tissues were first tested in the human non-cancerous RWPE-1 and in the cancerous LNCaP cell models, which allowed the illustration of the specificity of the antibodies. As shown in Fig. 2, CD9 staining was primarily evident for the cell surface, while staining for FASN was primarily cytoplasmic for both cell models, as expected. EGR-1 staining seemed to be somewhat more diffuse, in agreement with its reported possible localization in both the nucleus and the cytoplasm, depending on cellular type and context $(11,23)$. In addition, the expression level for all three markers was slightly higher in the LNCaP than in the RWPE-1 cells. Important for the use of the antibodies in human tissues, the isotype-matched unspecific control antibody resulted in minimal, if any, staining in both cell types.

The same antibodies and staining conditions were used to detect CD9, EGR-1 and FASN in human prostate tissues of the cancerous type, histologically normal tumor-adjacent, as well as disease-free specimens, as outlined in Table I. Due to the higher complexity of human tissues compared to cultured cells, the staining for all three protein markers was somewhat more diffuse, but nevertheless typical for the corresponding target, as shown in Fig. 3. A total of 336 digitized confocal images from 22 individual specimens were used for the quantification of signal intensity (expression) by computational detection of sum pixel count per area. The coefficients of variation ranges for CD9, EGR-1 and FASN expression were 14.5-17.7, 16.1-27.1 and 15.0-21.3\%, respectively (data not shown). These are consistent with previous findings by the authors $(7,10,11)$ and generally indicate the well-known intraand inter-tissue heterogeneity of expression. To acknowledge this heterogeneity, an inclusive approach was adopted, i.e., any computational determination of potential outliers was deemed unjustified, and all available images of sufficient quality were included for the analysis of expression. Group comparisons by ANOVA revealed significant differences between the types of tissues for all three markers $(\mathrm{P}<0.01)$. As shown in
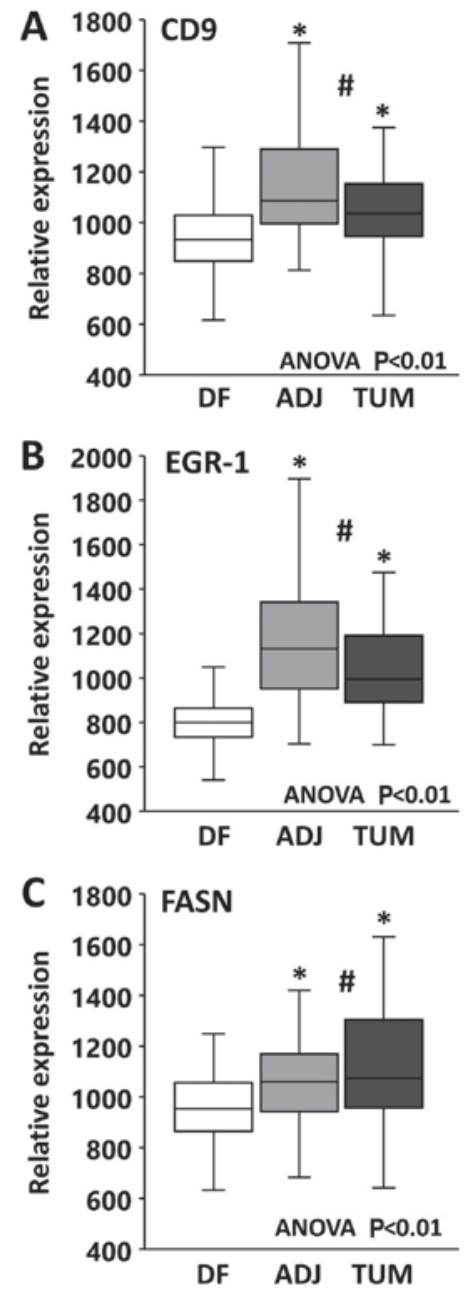

Figure 4. Relative expression of (A) CD9, (B) EGR-1, and (C) FASN in disease-free (DF), tumor-adjacent (ADJ) and tumor (TUM) human prostate tissues. The whisker plots/boxes represent group means (middle line) and quartiles (25th and 75th percentiles) at their ends; lines above and below boxes indicate the 10th and the 90th percentiles, respectively. The indicated P-values denote the level of statistical significance for the differences between groups, as calculated by single factor ANOVA. "P $\leq 0.05$, significant difference in means compared to DF tissues; ${ }^{\#} \mathrm{P}>0.05$, no significant difference in means between the ADJ and TUM groups. EGR-1, early growth response 1; FASN, fatty acid synthase.

Fig. 4A, CD9 mean expression was slightly, yet significantly higher in tumor $(1.1 \mathrm{x})$ and in tumor-adjacent $(1.2 \mathrm{x})$ compared to disease-free tissues $(\mathrm{P}<0.01)$, while it was similar between tumor and tumor-adjacent tissues $(\mathrm{P}>0.05)$. Similarly, as shown in Fig. 4B, EGR-1 mean expression in tumor (1.3x) and tumor-adjacent (1.5x) tissues was slightly, yet significantly elevated compared to disease-free tissues $(\mathrm{P}<0.01)$, while it was similar between tumor and tumor-adjacent tissues $(\mathrm{P}>0.05)$. Finally, the same mean expression pattern was observed for FASN (Fig. 4C), with expression levels in tumor (1.2x) and tumor-adjacent (1.1x) being slightly, yet significantly higher than in disease-free tissues $(\mathrm{P}<0.01)$ and similar between tumor and tumor-adjacent tissues $(\mathrm{P}>0.05)$. Taken together, these results corroborate the field cancerized nature of tissues adjacent to prostate adenocarcinomas.

Correlation between CD9, EGR-1 and FASN expression in human prostate tissues. In a previous study, the authors 


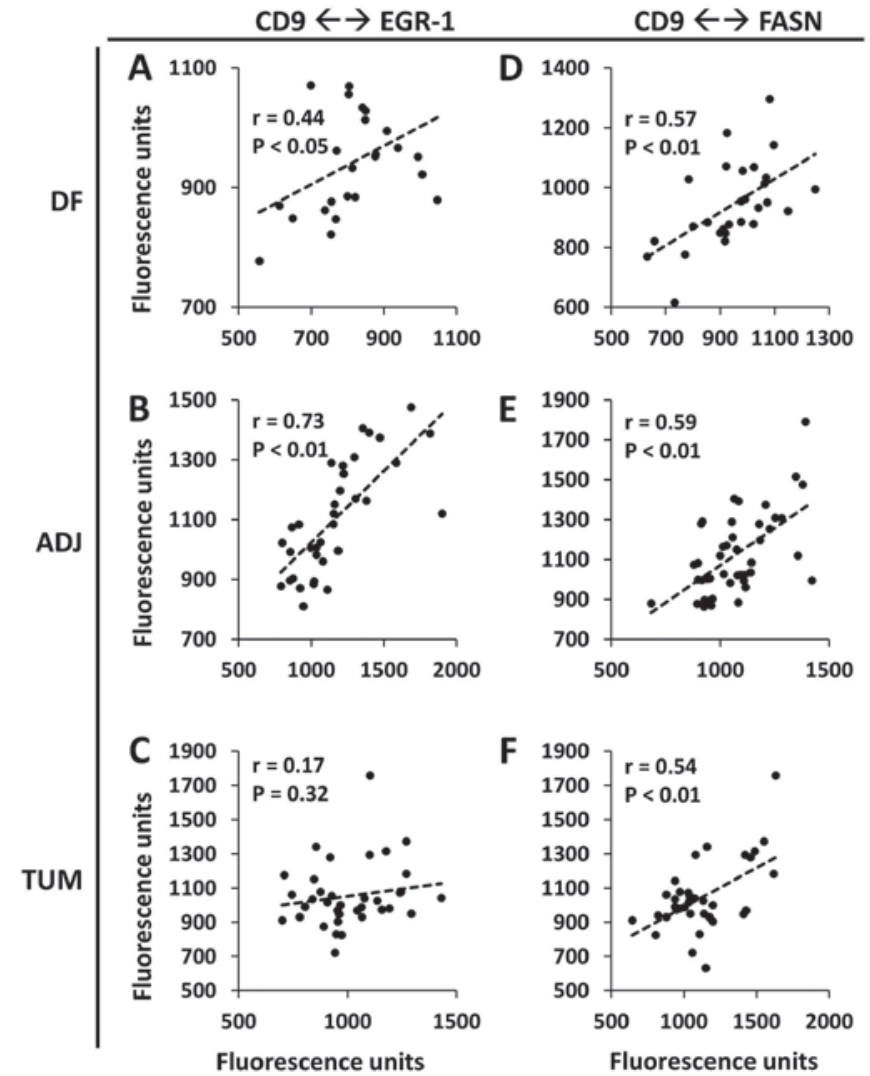

Figure 5. Correlation analysis between CD9 and (A-C) EGR-1 and between (D-F) CD9 and FASN in disease-free (DF), tumor-adjacent (ADJ) and tumor (TUM) human prostate tissues. The $\mathrm{x}$ - and $\mathrm{y}$-axes of the scatter plots represent relative expression in units of fluorescence, as calculated by the NIS-Elements AR 4.30.02/64bit software. Each dot represents a measurement data point and the dotted line represents the best fit of correlation. ' $r$ ' denotes the Pearson's correlation. The P-value denotes the significance for the Pearson's correlation based on the t-value of the correlation and the two-tailed Student t-distribution. Statistical significance is defined as $\mathrm{P} \leq 0.05$. EGR-1, early growth response 1; FASN, fatty acid synthase.

reported on the correlation between EGR-1 and other field cancerization markers, i.e., platelet-derived growth factor A (PDGF-A), macrophage inhibitory cytokine 1 (MIC-1) and FASN (7), with the question in mind of whether EGR-1, as a master transcription factor, could be a regulator of the other three factors. Similarly, one major objective of the present study was to explore the possibility that exosomes are effectors of field cancerization in prostate tissues. Thus, this study aimed to determine a potential association between the occurrence of CD9 and EGR-1, and between CD9 and FASN within the individual types of tissues analyzed in this study, and at determining whether such a correlation changes in these different types of tissues. This was possible by generating images at the same position on the TMAs that were consecutive sections approximately $5 \mu \mathrm{m}$ apart from each other, as shown in Fig. 1. Correlations between CD9 and EGR-1, and between CD9 and FASN were determined by Pearson's correlation analysis, which is by default amenable to both positive and negative correlations. Of particular interest was to determine whether possible correlations differ between different types of tissues, i.e., disease-free, tumor-adjacent and tumor tissues. Pearson's correlations between CD9 and EGR-1 were $r=0.44$ $(\mathrm{P}<0.05), \mathrm{r}=0.73(\mathrm{P}<0.01)$ and $\mathrm{r}=0.17(\mathrm{P}=0.32)$ in disease-free, tumor-adjacent and tumor tissues, respectively (Fig. 5A-C). Pearson's correlations between CD9 and FASN were $\mathrm{r}=0.57$ $(\mathrm{P}<0.01), \mathrm{r}=0.59(\mathrm{P}<0.01)$ and $\mathrm{r}=0.54(\mathrm{P}<0.01)$ in disease-free, tumor-adjacent and tumor tissues, respectively (Fig. 5D-F). The strongest correlations between CD9 and EGR-1, and between CD9 and FASN were thus observed in tumor-adjacent tissues. Given the rather high level of heterogeneity, these values were deemed to be markedly high. Since CD9 expression represents exosome formation and excretion (24-26) and EGR-1 is a marker of field cancerization $(7,11)$, these results suggest a potential role of exosomes in the formation of field cancerization.

Effect of exosomes from cancerous cells on non-cancerous cells. The potential of exosomes derived from cancer cells to induce the expression of field cancerization markers, such as EGR-1 and FASN in non-cancerous cells was experimentally examined using the non-cancerous RWPE- 1 and the cancerous LNCaP cell models. The golden standard method was used, i.e., ultracentrifugation, to isolate exosomes from $\mathrm{LNCaP}$ and RWPE-1 cells and determined their protein concentration. Consistently, it was calculated that $1 \mu \mathrm{g}$ exosomal protein was produced by approximately 300,000 cells under standard growth conditions during $24 \mathrm{~h}$ of culture. Atomic force microscopic analysis of the LNCaP and RWPE-1 exosomes (Fig. 6) revealed horizontal and vertical dimensions of $74.6 \pm 26.2$ and $78.0 \pm 28.4 \mathrm{~nm}$ for the LNCaP cells (Fig. 6A), and 89.6 \pm 31.4 and $93.6 \pm 34.0 \mathrm{~nm}$ for the RWPE-1 cells (Fig. 6B), respectively. This size is in agreement with that of numerous previous reports on exosomes from cells of prostatic origin (17-20). LNCaP and RWPE-1 exosomes were also analyzed biochemically by western blot analysis, along with the corresponding cells that secreted them (Fig. 7). Immunodetection using specific antibodies revealed the presence of CD9 in both exosomes and cells. In accordance with previously reported proteomic profiles of exosomes secreted by prostate cells (24), actin and FASN were also detected in both LNCaP cells and exosomes, although FASN expression was under the detection limit for RWPE-1 cells. However, another study did not report the presence of FASN in LNCaP exosomes, but instead reported the presence of AR (26), which we did not find in either cell types. These discrepancies may be due to different culture conditions, collection times, and other experimental and/or analytical parameters. EGR-1 was detected in the cellular extracts, but not in the exosomal lysates, which is congruent with its absence in the previously reported proteomic profiles $(24,26)$. Finally, the AR was expressed in LNCaP cells, but was virtually absent in RWPE- 1 cells if not induced by excess androgen as reported (ATCC) (Fig. 7).

To examine the effect of prostate cancer cell-derived exosomes on the expression of the two field cancerization markers EGR-1 and FASN in non-cancerous prostate cells, the RWPE-1 cells were treated with LNCaP-derived exosomes at a 3:1 and 30:1 cell-to-cell ratio for $16 \mathrm{~h}$. The protein profiles of the lysates of the treated RWPE-1 cells did not appear to be different from the control, suggesting that the exosomes did not induce major expressional changes (data not shown). Western blot analysis revealed an inducive effect of up to 3.5-fold, for EGR-1, but only up to 1.5-fold for FASN (Fig. 8). FASN protein has previously been demonstrated to be part 
A
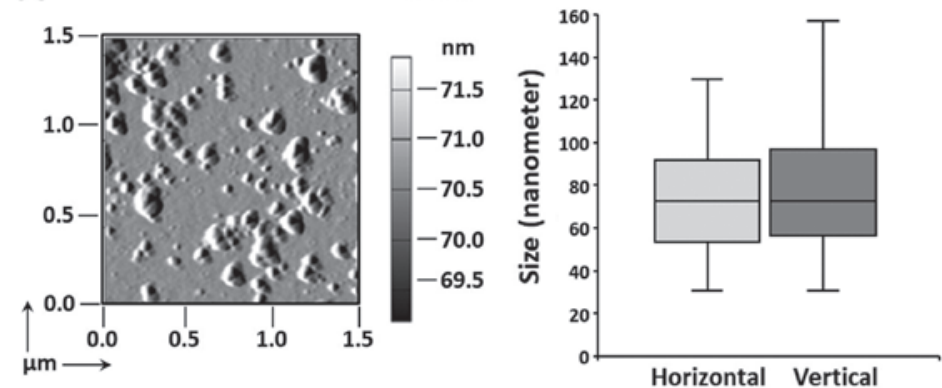

B

RWPE-1
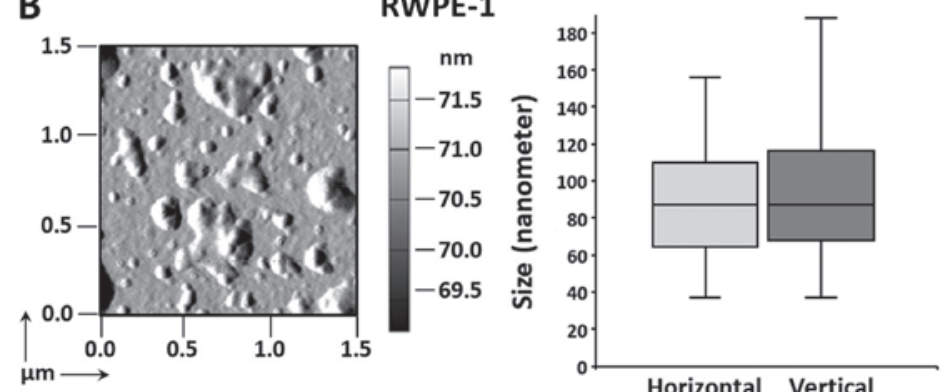

Figure 6. Characterization of cancerous (A) LNCaP and non-cancerous (B) RWPE-1 prostate cell-derived exosomes. The left panels illustrate the atomic force microscopic image of exosomes. The distances (in $\mu \mathrm{m}$ ) are indicated on the $\mathrm{x}$ - and $\mathrm{y}$-axes. The grey scale bars on the right indicate the height of the particles. The right panels illustrate the horizontal and vertical size distribution (in $\mathrm{nm}$ ) of the particles. The whisker plots/boxes represent group means (middle line) and quartiles (25th and 75th percentiles) at their ends; lines above and below boxes indicate the 10th and the 90th percentiles, respectively. EGR-1, early growth response 1 ; FASN, fatty acid synthase.

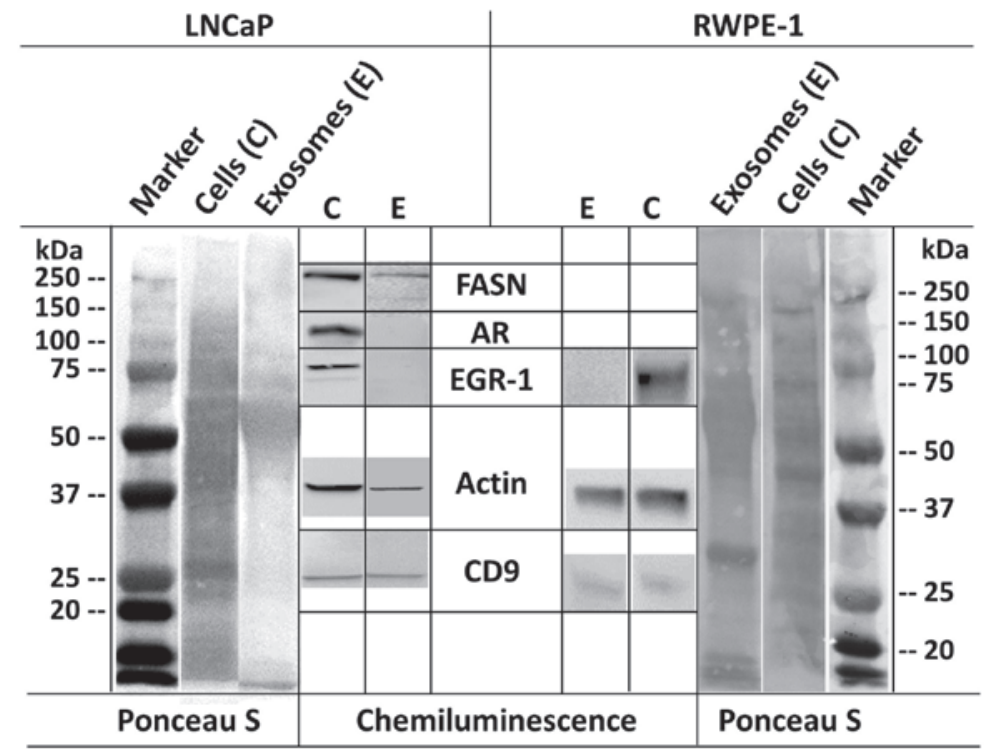

Figure 7. Detection of CD9, FASN, AR, EGR-1 and actin in LNCaP and RWPE-1 cells (represented by 'C') and exosomes (represented by 'E') by western blot analysis/chemiluminescence. The standard marker and the protein profiles are stained with Ponceau S dye. EGR-1, early growth response 1; FASN, fatty acid synthase.

of the exosomal content released by prostate cells (24). Thus, in order to demonstrate that a possible inducive expression was due to transcriptional activation, the induction of FASN mRNA was measured by RT-qPCR. At lower concentrations of exosomes, FASN mRNA transcription was induced approximately 10-fold. Similarly, EGR-1 mRNA was induced approximately 8-fold (Fig. 9). Overall, these results are in good agreement with the observations made in the tissues and suggest a regulatory association between exosome release and FASN and EGR-1 expression in human prostate tissues.

\section{Discussion}

Several reviews of molecular pathology known as field cancerization, or the field effect, have emphasized its potential to improve the clinical management of solid tumors, including 

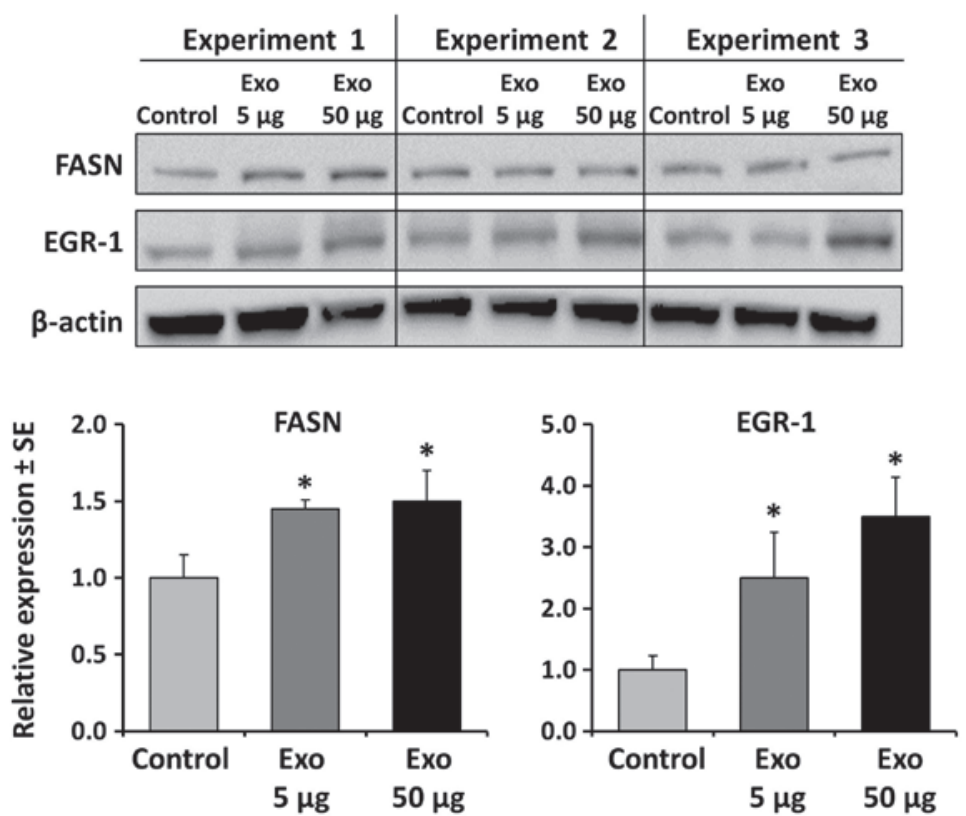

Figure 8. Effect of LNCaP prostate cancer cell-derived exosomes ( 5 or $50 \mu \mathrm{g}$ ) on non-cancerous RWPE-1 prostate cells. The top panel illustrates relative protein expression of FASN and EGR-1 in RWPE-1 cells treated with LNCaP-derived exosomes (Exo) or with $50 \mu \mathrm{g}$ exosomes from non-cancerous RWPE-1 cells (control). $\beta$-actin was used as a protein loading control. The bottom panel illustrates the quantification of chemiluminescent detection of FASN and EGR-1 by densitometry (ImageJ software). Bars show the average of 3 independent experiments [ \pm standard error (SE)] and represent the ratio of FASN and EGR-1 with $\beta$-actin signal (control) set to 1.0 and FASN and EGR-1 compared to RWPE-1 exosome control. ${ }^{*} \mathrm{P} \leq 0.05$, statistical significance compared to the control. EGR-1, early growth response 1; FASN, fatty acid synthase.

prostate cancer $(6,13,14,27)$. In this regard, it is conceivable that the molecular aberrations, be it of genetic, epigenetic and/or biochemical nature, could act as biomarkers along the entire development of the disease and/or as molecular targets for preventative or interventive therapy. The authors have previously contributed to the identification of markers of prostate field cancerization and have reported on their potential clinical uses, thereby validating some of them (7-13). Accordingly, the authors have previously reported on two recurrent markers of field cancerization, i.e., the key transcription factor and master regulator, EGR-1, and the lipogenic enzyme, FASN, specifically their upregulation at the protein level in histologically normal tissue adjacent to prostate tumors when compared to disease-free, truly normal prostatic tissues $(7,8,11)$. It is not inconceivable that such molecular aberrations could be used for example, to improve the diagnosis of prostate cancer in false-negative biopsies (13). The latter continue to challenge confirmatory diagnoses of prostate adenocarcinoma following an abnormal prostate-specific antigen (PSA) test or suspicious digital rectal examination (DRE) (28-31). In this scenario, tissue affected by field cancerization increases the clinically informative area under microscopic analysis by the surgical pathologist when combined with immunological techniques. This could lead to a reduction of repeat biopsies and thus, a more effective clinical management. The possibility to predict the existence of lesions in a tissue without their visual detection has prompted others to call tissues affected by field cancerization 'TINT', for 'tumor indicating normal tissue' (32). Even in the case of a positive detection of cancerous tissue in biopsies, markers of field cancerization could have a meaningful application. The clinical setting referred to here is active surveillance, which is increasingly chosen by patients diagnosed with low-risk prostate cancer, defined as low number

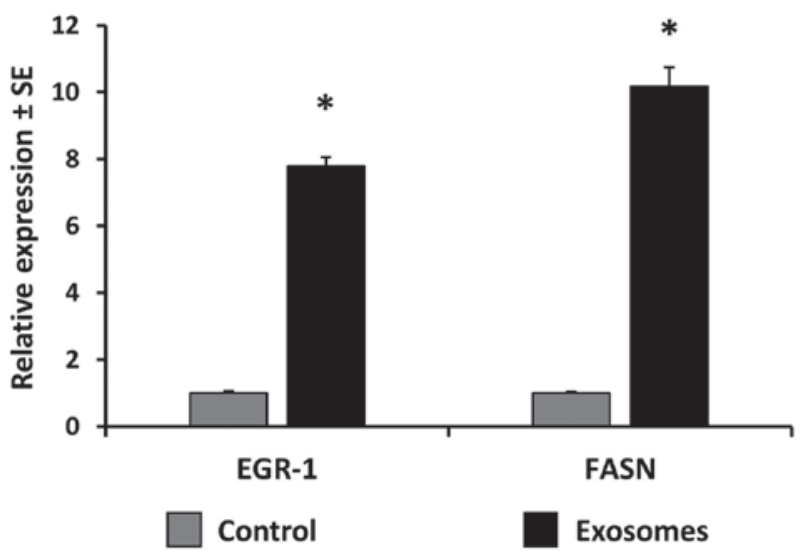

Figure 9. Effect of LNCaP prostate cancer cell-derived exosomes on non-cancerous RWPE-1 prostate cells. Relative mRNA expression of FASN and EGR-1 in RWPE-1 cells treated with LNCaP-derived or RWPE-1-derived exosomes (control). Bars show the average of 3 independent experiments [ \pm standard error (SE)]. Control is set to 1.0 and FASN and EGR-1 are compared to the control. ${ }^{\text {P }} \leq 0.05$, statistical significance compared to the control. EGR-1, early growth response 1; FASN, fatty acid synthase.

of positive biopsy cores, low $\%$ of tissue affected and low Gleason grade $(33,34)$. Active surveillance programs are meant to defer more aggressive treatments of curative intent but with quality of life lowering side effects, including radical prostatectomy $(35,36)$. These programs include frequent PSA testing and the histological examination of repeat biopsies to monitor potential cancer progression. It is thus conceivable that well-defined areas, markers and parameters of field cancerization could be monitored during this time. Similarly, the effect of neoadjuvant therapeutic interventions could be assessed during this pre-surgical setting $(13,37)$. The extent 
of field cancerization could also be indicative of a positive surgical margin, which is an important clinical parameter in the administration of focal therapy, a less invasive therapeutic modality on the rise $(13,38)$. In this scenario, the presence of a field effect at the margin may be indicative of an elevated risk for progression or of the extent of tumor multifocality within the prostate (39). Lastly, given the widely accepted premise that the observed molecular aberrations in histologically normal tissues constitute a state of pre-malignancy, markers of field cancerization could represent targets for therapeutic intervention $(13,32)$.

Regardless of the potential clinical application, it is widely accepted that the molecular etiology of field cancerization should be understood in order to fully benefit from it. It is thus important to identify the distinct cellular and molecular mechanisms and pathways that result in the molecular aberrations observed in tissues affected by a field effect. For example, for the afore-mentioned protein factors EGR-1 and FASN, the events that lead to their upregulation in histologically normal tissues adjacent to existing prostate tumors remain unknown. Thus, it would be of interest to determine the mechanisms through which a prostate tumor lesion influences its surrounding tissues, thereby potentially priming it for the induction of multifocal disease. As is well-known from 2019, the role of exosomes in cell-to-cell and in tissue-to-tissue communication has been established and proven to be a major mode of physiological and reciprocal interactions in multicellular organisms $(15,16)$. While studies of exosomes of prostatic origin tend to focus on their application as biomarkers in liquid biopsy schemes and on the molecular characterization of their content (17-20), reports on specific exosomal factors on the genotype and phenotype of recipient cells are now increasing in number. For example, prostate cancer cell-derived exosomes have been shown to inhibit and promote osteoclast and osteoblast cell activity, respectively $(40,41)$, which could promote the overall osteoblastic phenotype of prostate cancer metastases. Exosomes shed by prostate cancer cells have been shown to carry integrin $\alpha v \beta 3$ which, when deposited in recipient cells, is postulated to increase their motility (42). Similarly, the motility of stromal cells has been shown to increase by prostate cancer exosomes (43). Hypoxia-induced exosomes lead to increased prostate cell survival and invasiveness by targeting molecules of the adherens junctions $(44,45)$, while the exosomal factor and tetraspanin CD9 promotes prostate cancer cell growth under androgen-deprived conditions (46). Based on such reports, the existence of a new link has been hypothesized between cancer cell-derived exosomes and the induction of field cancerization. Accordingly, the present study attempted for the first time, at least to the best of our knowledge, to demonstrate a quantitative association between the exosomal marker, CD9, and our previously identified markers of field effect, EGR-1 and FASN. This study on a pilot tissue cohort indicates a positive correlation between CD9 expression on one side and EGR-1 and FASN expression on the other, with the link with the former factor being more significant. The authors have previously demonstrated that these two factors are upregulated in prostate tissues resected $1 \mathrm{~cm}$ from the visible tumor margin at both the mRNA and protein level $(7,8,11)$. The induction of both factors in histologically normal areas of the prostate by tumor-derived exosomes is congruent with our hypothesis of a 'priming', potentially tumor-promoting effect. EGR-1 is a central transcription regulator of a number of molecular pathways and acts divergently according to the cell context $(23,47,48)$. However, in prostate tumors it acts as a promoter of cancer progression $(47,49,50)$. FASN is equally established in prostate cancer and has been termed a metabolic oncogene. It promotes tumor cell proliferation through lipid biosynthesis and the post-translational modification of proteins and is the focus of ongoing efforts to develop specific inhibitors of its enzymatic activity $(51,52)$. Of note, the authors have previously demonstrated a potential regulatory function of EGR-1 for FASN expression (7). Overall, the data presented in this report corroborates in an independent tissue cohort and data set that EGR-1 and FASN are recurrent markers of prostate field cancerization. Of note, the magnitude of the overexpression of EGR-1 and FASN in field cancerized prostate tissues can vary in independent studies due to tissue heterogeneity and to the type of antibodies used. Of note however, the present study independently corroborates the previous findings by the authors $(7,10,11)$. In addition, for both factors, future studies are required to include testing whether their transcriptional and enzymatic activities, respectively, are also heightened in field cancerized tissues. As a novel observation, the data of the present study demonstrate that CD9 expression contributes similarly to this phenomenon through its change (increase) from disease-free to tumor-adjacent and to histologically cancerous tissues. The authors acknowledge the possibility that the observed CD9 staining in the tissues can be due to its documented expression in prostate gland epithelial cells (proteinatlas.org). Since CD9 is also a proven exosomal marker (24), it is not inconceivable that the observed expression is representative of exosomal release. However, the findings of this study need to be corroborated in follow-up studies using additional exosomal markers, including for example CD63 (53). Importantly, the results of this study support the notion that exosomes released by cancerous lesions in the prostate could induce the upregulation of factors that promote the biochemical transformation of physiologically and phenotypically normal cells, leading to the formation of molecularly altered fields. For EGR-1, the data of this study are congruent with those of other studies in other cell systems, where exosomes exert their actions through EGR-1 expression and activation, for example in muscle cells affected by exosomes released by adipose cells (54).

For the most part, in this study, the in vitro data using the LNCaP and the RWPE-1 cell models support the associations made in situ in human tissues, although the link between CD9 (exosomes) and EGR-1 (field effect) is clearer. With respect to FASN, this study prompts for caution when comparing observations made in tissues with those made in cell models. This is due to the fact that FASN may be part of the 'cargo' of exosomes released by prostate cancer cells, although conflicting results exist $(24,26)$. Of note, the results of this study support the those of the study by Duijvesz et al (24). Thus, an elevated FASN expression in field cancerization may be, at least in part, directly due to exosomal FASN delivery. The in vitro experiments of this study, however, indicate de 
novo induction of FASN mRNA, which, for the most part, is accompanied by corresponding protein levels. The FASN experiments performed herein warrant further investigations using functional approaches in systems that reflect the complexity of human tissues. The same may be true for the $\mathrm{AR}$, the presence of which in prostate exosomes is equally inconclusive $(24,26)$. It is known that in cultured cells, the physiological complexity is relatively low and may not reflect entirely the complex regulatory networks at work in tissues. With respect to the latter, it can be argued that tissue studies are static and compromised by sample heterogeneity. However, they are also physiologically relevant and better reflect the complexity of cellular and molecular pathways influenced by the environment, for example in animal models. Importantly, it is demonstrated herein that when coupled with sophisticated and quantitative data acquisition methods, they can deliver meaningful indications of molecular associations in a physiologically relevant in situ environment, even in the presence of high heterogeneity. As it is widely accepted that field effect represents a pre-malignant state, such knowledge may aid in the development of targeted intervention strategies preventing progression of pre-malignancy to cancer.

\section{Acknowledgements}

The authors would like to thank Dr Molla Islam of the Chemistry and Biochemistry Division of Chapman University Schmid College of Science and Technology for analyzing the LNCaP and RWPE-1 exosomes by atomic force microscopy. The departmental office and staff of the Chapman University Schmid College of Science and Technology are acknowledged for providing administrative support.

\section{Funding}

This study was supported by the Department of Defense Prostate Cancer Research Program grant no. W81XWH-15-1-0056 (to MB), and by grants from the Chapman University Center for Undergraduate Excellence (to PAP, JPTN and ELC), and a generous gift from Melinda and Edward Subia of Orange County CA.

\section{Availability of data and materials}

The datasets used and/or analyzed during the current study are available from the corresponding author on reasonable request.

\section{Authors' contributions}

The authors' significant contributions to this study were the following: FA and PAP were involved in cell and tissue immunofluorescence and analysis. NSP and JPTN were involved in exosome isolation and characterization. JPTN and ELC were involved in western blot analysis and RT-qPCR. ACJ was involved in immunofluorescence protocol development and study concept design. MB was involved in the conception and design of the study, the procurement and management of funding, supervision, data analysis and in the writing of the manuscript. All authors have read and approved the final manuscript.

\section{Ethics approval and consent to participate}

In the present study, tissue microarrays (TMAs) used. No human tissues from other sources, other than commercially available TMAs, were used in the present study. The use of any human tissues, including commercially available TMAs, is covered by the Chapman University Institutional Review Board (IRB) study \#1415H024. Experiments with human tissues was approved by the Institutional Review Board of Chapman University.

\section{Patient consent for publication}

Not applicable.

\section{Competing interests}

The authors declare that they have no competing interests.

\section{References}

1. Slaughter DP, Southwick HW and Smejkal W: Field cancerization in oral stratified squamous epithelium; clinical implications of multicentric origin. Cancer 6: 963-968, 1953.

2. Angadi PV, Savitha JK, Rao SS and Sivaranjini Y: Oral field cancerization: Current evidence and future perspectives. Oral Maxillofac Surg 16: 171-180, 2012.

3. Braakhuis BJ, Tabor MP, Kummer JA, Leemans CR and Brakenhoff RH: A genetic explanation of Slaughter's concept of field cancerization: Evidence and clinical implications. Cancer Res 63: 1727-1730, 2003.

4. Curtius K, Wright NA and Graham TA: An evolutionary perspective on field cancerization. Nat Rev Cancer 18: 19-32, 2018

5. Takeshima $\mathrm{H}$ and Ushijima $\mathrm{T}$ : Accumulation of genetic and epigenetic alterations in normal cells and cancer risk. NPJ Precis Oncol 3: 7, 2019.

6. Lochhead P, Chan AT, Nishihara R, Fuchs CS, Beck AH, Giovannucci E and Ogino S: Etiologic field effect: Reappraisal of the field effect concept in cancer predisposition and progression. Mod Pathol 28: 14-29, 2015.

7. Gabriel KN, Jones AC, Nguyen JP, Antillon KS, Janos SN, Overton HN, Jenkins SM, Frisch EH, Trujillo KA and Bisoffi M: Association and regulation of protein factors of field effect in prostate tissues. Int J Oncol 49: 1541-1552, 2016

8. Haaland CM, Heaphy CM, Butler KS, Fischer EG, Griffith JK and Bisoffi M: Differential gene expression in tumor adjacent histologically normal prostatic tissue indicates field cancerization. Int J Oncol 35: 537-546, 2009.

9. Heaphy CM, Fleet TM, Treat EG, Lee SJ, Smith AY, Davis MS Griffith JK, Fischer EG and Bisoffi M: Organ-wide telomeric status in diseased and disease-free prostatic tissues. Prostate 70: 1471-1479, 2010.

10. Jones AC, Antillon KS, Jenkins SM, Janos SN, Overton HN, Shoshan DS, Fischer EG, Trujillo KA and Bisoffi M: Prostate field cancerization: Deregulated expression of macrophage inhibitory cytokine 1 (MIC-1) and platelet derived growth factor A (PDGF-A) in tumor adjacent tissue. PLoS One 10: e0119314, 2015.

11. Jones AC, Trujillo KA, Phillips GK, Fleet TM, Murton JK, Severns V, Shah SK, Davis MS, Smith AY, Griffith JK, et al: Early growth response 1 and fatty acid synthase expression is altered in tumor adjacent prostate tissue and indicates field cancerization. Prostate 72: 1159-1170, 2012.

12. Treat EG, Heaphy CM, Massie LW, Bisoffi M, Smith AY, Davis MS and Griffith JK: Telomere DNA content in prostate biopsies predicts early rise in prostate-specific antigen after radical prostatectomy for prostate cancer. Urology 75: 724-729, 2010.

13. Trujillo KA, Jones AC, Griffith JK and Bisoffi M: Markers of field cancerization: Proposed clinical applications in prostate biopsies. Prostate Cancer 2012: 302894, 2012.

14. Nonn L, Ananthanarayanan V and Gann PH: Evidence for field cancerization of the prostate. Prostate 69: 1470-1479, 2009. 
15. Choi JY, Kim S, Kwak HB, Park DH, Park JH, Ryu JS, Park CS and Kang JH: Extracellular Vesicles as a Source of Urological Biomarkers: Lessons Learned From Advances and Challenges in Clinical Applications to Major Diseases. Int Neurourol J 21: 83-96, 2017.

16. Dhondt B, Van Deun J, Vermaerke S, de Marco A, Lumen N, De Wever $\mathrm{O}$ and Hendrix A: Urinary extracellular vesicle biomarkers in urological cancers: From discovery towards clinical implementation. Int J Biochem Cell Biol 99: 236-256, 2018.

17. Pan J, Ding M, Xu K, Yang C and Mao LJ: Exosomes in diagnosis and therapy of prostate cancer. Oncotarget 8: 97693-97700, 2017.

18. Vlaeminck-Guillem V: Extracellular Vesicles in Prostate Cancer Carcinogenesis, Diagnosis, and Management. Front Oncol 8 : 222, 2018.

19. Panigrahi GK and Deep G: Exosomes-based biomarker discovery for diagnosis and prognosis of prostate cancer. Front Biosci 22: 1682-1696, 2017

20. Soekmadji C, Russell PJ and Nelson CC: Exosomes in prostate cancer: Putting together the pieces of a puzzle. Cancers (Basel) 5 : $1522-1544,2013$

21. Fordyce CA, Heaphy CM, Joste NE, Smith AY, Hunt WC and Griffith JK: Association between cancer-free survival and telomere DNA content in prostate tumors. J Urol 173: 610-614, 2005.

22. Livak KJ and Schmittgen TD: Analysis of relative gene expression data using real-time quantitative PCR and the 2(-Delta Delta C(T)) Method. Methods 25: 402-408, 2001.

23. Mora GR, Olivier KR, Cheville JC, Mitchell RF Jr, Lingle WL and Tindall DJ: The cytoskeleton differentially localizes the early growth response gene-1 protein in cancer and benign cells of the prostate. Mol Cancer Res 2: 115-128, 2004.

24. Duijvesz D, Burnum-Johnson KE, Gritsenko MA, Hoogland AM, Vredenbregt-van den Berg MS, Willemsen R, Luider T, Paša-Tolić L and Jenster G: Proteomic profiling of exosomes leads to the identification of novel biomarkers for prostate cancer. PLoS One 8: e82589, 2013.

25. Malla RR, Pandrangi S, Kumari S, Gavara MM and Badana AK: Exosomal tetraspanins as regulators of cancer progression and metastasis and novel diagnostic markers. Asia Pac J Clin Oncol 14: 383-391, 2018.

26. Mizutani K, Terazawa R, Kameyama K, Kato T, Horie K, Tsuchiya T, Seike K, Ehara H, Fujita Y, Kawakami K, et al: Isolation of prostate cancer-related exosomes. Anticancer Res 34 3419-3423, 2014

27. Dakubo GD, Jakupciak JP, Birch-Machin MA and Parr RL: Clinical implications and utility of field cancerization. Cancer Cell Int 7: 2, 2007.

28. Bjurlin MA, Meng X, Le Nobin J, Wysock JS, Lepor H, Rosenkrantz AB and Taneja SS: Optimization of prostate biopsy: The role of magnetic resonance imaging targeted biopsy in detection, localization and risk assessment. J Urol 192: 648-658, 2014.

29. Bostanci Y, Kazzazi A and Djavan B: Optimizing prostate biopsy. Minerva Urol Nefrol 64: 233-243, 2012.

30. Delongchamps NB and Haas GP: Saturation biopsies for prostate cancer: Current uses and future prospects. Nat Rev Urol 6: 645-652, 2009

31. Rabbani F, Stroumbakis N, Kava BR, Cookson MS and Fair WR: Incidence and clinical significance of false-negative sextant prostate biopsies. J Urol 159: 1247-1250, 1998.

32. Halin S, Hammarsten P, Adamo H, Wikström P and Bergh A: Tumor indicating normal tissue could be a new source of diagnostic and prognostic markers for prostate cancer. Expert Opin Med Diagn 5: 37-47, 2011.

33. Mazzucchelli R, Galosi AB, Santoni M, Lopez-Beltran A, Scarpelli M, Cheng L and Montironi R: Role of the pathologist in active surveillance for prostate cancer. Anal Quant Cytopathol Histpathol 37: 65-68, 2015.

34. Pomerantz M: Active Surveillance: Pathologic and Clinical Variables Associated with Outcome. Surg Pathol Clin 8: 581-585, 2015.
35. Bellardita L, Valdagni $\mathrm{R}$, van den Bergh $\mathrm{R}$, Randsdorp $\mathrm{H}$, Repetto C, Venderbos LD, Lane JA and Korfage IJ: How does active surveillance for prostate cancer affect quality of life? A systematic review. Eur Urol 67: 637-645, 2015.

36. Kwon $\mathrm{O}$ and Hong S: Active surveillance and surgery in localized prostate cancer. Minerva Urol Nefrol 66: 175-187, 2014.

37. Lou DY and Fong L: Neoadjuvant therapy for localized prostate cancer: Examining mechanism of action and efficacy within the tumor. Urol Oncol 34: 182-192, 2016.

38. Marshall S and Taneja S: Focal therapy for prostate cancer: The current status. Prostate Int 3: 35-41, 2015.

39. Andreoiu M and Cheng L: Multifocal prostate cancer: Biologic, prognostic, and therapeutic implications. Hum Pathol 41: 781-793, 2010.

40. Duan Y, Tan Z, Yang M, Li J, Liu C, Wang C, Zhang F, Jin Y, Wang Y and Zhu L: PC-3-Derived Exosomes Inhibit Osteoclast Differentiation by Downregulating miR-214 and Blocking NF-кB Signaling Pathway. BioMed Res Int 2019: 8650846, 2019.

41. Li SL, An N, Liu B, Wang SY, Wang JJ and Ye Y: Exosomes from LNCaP cells promote osteoblast activity through miR-375 transfer. Oncol Lett 17: 4463-4473, 2019.

42. Krishn SR, Singh A, Bowler N, Duffy AN, Friedman A, Fedele C, Kurtoglu S, Tripathi SK, Wang K, Hawkins A, et al: Prostate cancer sheds the $\alpha v \beta 3$ integrin in vivo through exosomes. Matrix Biol 77: 41-57, 2019.

43. McAtee CO, Booth C, Elowsky C, Zhao L, Payne J, Fangman T, Caplan S, Henry MD and Simpson MA: Prostate tumor cell exosomes containing hyaluronidase Hyall stimulate prostate stromal cell motility by engagement of FAK-mediated integrin signaling. Matrix Biol 78-79: 165-179, 2019.

44. Panigrahi GK, Praharaj PP, Peak TC, Long J, Singh R, Rhim JS, Abd Elmageed ZY and Deep G: Hypoxia-induced exosome secretion promotes survival of African-American and Caucasian prostate cancer cells. Sci Rep 8: 3853, 2018.

45. Ramteke A, Ting H, Agarwal C, Mateen S, Somasagara R, Hussain A, Graner M, Frederick B, Agarwal R and Deep G: Exosomes secreted under hypoxia enhance invasiveness and stemness of prostate cancer cells by targeting adherens junction molecules. Mol Carcinog 54: 554-565, 2015.

46. Soekmadji C, Riches JD, Russell PJ, Ruelcke JE, McPherson S, Wang C, Hovens CM, Corcoran NM, Hill MM and Nelson CC; Australian Prostate Cancer Collaboration BioResource: Modulation of paracrine signaling by CD9 positive small extracellular vesicles mediates cellular growth of androgen deprived prostate cancer. Oncotarget 8: 52237-52255, 2016.

47. Gitenay D and Baron VT: Is EGR1 a potential target for prostate cancer therapy? Future Oncol 5: 993-1003, 2009.

48. Pagel JI and Deindl E: Early growth response 1 - a transcription factor in the crossfire of signal transduction cascades. Indian J Biochem Biophys 48: 226-235, 2011.

49. Adamson E, de Belle I, Mittal S, Wang Y, Hayakawa J, Korkmaz K, O'Hagan D, McClelland M and Mercola D: Egr1 signaling in prostate cancer. Cancer Biol Ther 2: 617-622, 2003.

50. Adamson ED and Mercola D: Egr1 transcription factor: Multiple roles in prostate tumor cell growth and survival. Tumour Biol 23: 93-102, 2002

51. Baron A, Migita T, Tang D and Loda M: Fatty acid synthase: A metabolic oncogene in prostate cancer? J Cell Biochem 91: 47-53, 2004.

52. Zadra G, Photopoulos C and Loda M: The fat side of prostate cancer. Biochim Biophys Acta 1831: 1518-1532, 2013.

53. Duijvesz D, Versluis CY, van der Fels CA, Vredenbregt-van den Berg MS, Leivo J, Peltola MT, Bangma CH, Pettersson KS and Jenster G: Immuno-based detection of extracellular vesicles in urine as diagnostic marker for prostate cancer. Int J Cancer 137: 2869-2878, 2015

54. Pan J, Alimujiang M, Chen Q, Shi H and Luo X: Exosomes derived from miR-146a-modified adipose-derived stem cells attenuate acute myocardial infarction-induced myocardial damage via downregulation of early growth response factor $1 . \mathrm{J}$ Cell Biochem 120: 4433-4443, 2019. 